\title{
El razonamiento bioético y la orientación hacia responsabilidad social empresarial de los estudiantes de negocios
}

\author{
Silvia López Paláu / slopez@coqui.net \\ Universidad de Puerto Rico \\ Recinto de Río Piedras
}

Beatriz Rivera-Cruz / acreditacionfae@yahoo.com

Universidad de Puerto Rico

Recinto de Río Piedras

RESUMEN:

Los conflictos éticos de la actualidad tienen una complejidad nunca antes vista que requieren la reflexión interdisciplinaria para su posible solución. El razonamiento bioético puede aportar al entendimiento y la solución de muchos conflictos éticos en el ámbito de los negocios. Este estudio examina si existe una relación entre la responsabilidad social empresarial y el razonamiento bioético utilizando como marco conceptual el modelo multidimensional de las empresas propuesto por Carroll (1979) y los principios bioéticos propuestos por Beauchamp y Childress (1979) y desarrolla instrumentos de medición confiables para ambos constructos. Los resultados obtenidos proveen información valiosa para diseñar nuevos enfoques en el adiestramiento ético de los individuos.

Palabras clave: bioética, responsabilidad social empresarial, género

\section{ABSTRACT:}

Ethical conflicts are ever more complex and require more interdisciplinary reflection to attain a solution. Bioethical reasoning can contribute to the understanding and eventual solution of many ethical conflicts in business. This study seeks to determine if a relationship exist among the social responsibility of business and the bioethical reasoning. A conceptual model using the multidimensional enterprise model proposed by Carroll (1979) and the bioethical principles proposed by Beauchamp and Childress (1979) is presented. A measurement instrument reliable for both constructs is developed. The results provide invaluable information that can help design new approaches for the ethical education of students.

Keywords: bioethics, corporate social responsibility, gender 


\section{INTRODUCCIÓN}

Los escándalos del mundo empresarial con los que se estrenó este siglo han traído una gran preocupación a las escuelas de negocios encargadas de educar a los gerentes y empresarios sobre la formación ética de los mismos. El debate sobre el rol de los negocios en la sociedad ha tomado un mayor auge cambiando la percepción tradicional que se tenía de las empresas como entes estrictamente económicos hacia ser vistas como organizaciones con obligaciones sociales. De igual forma, los desarrollos científicos (ej. genoma humano) y tecnológicos (ej. nanotecnología y biotecnología) plantean nuevos y diversos conflictos éticos impensables para las generaciones del pasado siglo. Además, la ideología neoliberal de las últimas décadas ha traído la tendencia de privatizar los servicios públicos. Por consiguiente, se ha reestructurado tanto de los gobiernos, que han cedido parte de sus funciones históricas, como la empresa privada, que ha incursionado en nuevos negocios, como son los servicios de salud. Servicios que antes eran prestados a la ciudadanía amparados por el sentido de justicia social de los Estados, hoy son prestados por organizaciones movidas por el lucro. También, las actividades humanas insensatas en la tierra han ido haciendo estragos en la salud ecológica del planeta llegando a amenazar la supervivencia misma de la especie. Todo esto plantea nuevos conflictos éticos de una complejidad nunca antes vista que requiere la reflexión interdisciplinaria para su posible solución.

La bioética comenzó estudiando las implicaciones morales y sociales de las tecnologías que resultaban de los avances de las ciencias biológicas. La ética empresarial ha dirigido sus esfuerzos a examinar los principios y problemas éticos que surgen en el mundo de los negocios, incluyendo la conducta de los individuos y de las organizaciones empresariales. La responsabilidad social empresarial es un movimiento que cobró mucho interés en los noventas. Es un modelo de gestión empresarial que incorpora las dimensiones económica, social y ambiental en sus operaciones en beneficio de los diferentes grupos con los que se relaciona, así como también atiende el a 
cuidado y preservación del entorno, mediante el cumplimiento de sus obligaciones legales y éticas. Si bien, en un principio, los temas de interés de estas tres áreas del conocimiento parecían no tener mucha vinculación, los conflictos éticos de hoy (tales como la contaminación ambiental, la pobreza, la inequidad, el acceso a servicios médicos, etc.) parecen ser una invitación a su integración. De hecho, en muchas escuelas de negocios los temas de ética empresarial y de responsabilidad social empresarial ya son parte del currículo, no tanto así la bioética que sigue mayoritariamente en las escuelas de medicina.

Algunos autores han hecho el ejercicio teórico de demostrar la utilidad de los principios bioéticos (autonomía, beneficencia, no maleficencia y justicia) en el análisis de situaciones empresariales (Wicks, 1995; Okada, 2008; Fisher, 2001), pero no se han desarrollado instrumentos de medición del razonamiento bioético ni de su posible vinculación con la responsabilidad social empresarial. Otros han desarrollado instrumentos de medición de la percepción de los estudiantes y administradores sobre el vínculo entre la responsabilidad social empresarial y la efectividad de las empresas (Sleeper, 2006; Singhapakdi, 1996; Aupperle, 1985), pero ninguno ha establecido un vínculo teórico entre la responsabilidad social empresarial y el razonamiento bioético. La mayor parte de los estudios se han basado en el modelo propuesto por Carroll (1979) que establece que las empresas funcionan en cuatro dimensiones (económica, legal, ética y de libre discreción).

El género ha sido una de las variables personales más estudiadas en las investigaciones éticas (Luthar et al., 2005; Gump et al., 2000; Roxas et al., 2004; Cohen et al., 1998; McGee et al., 2008; Patterson, 1994). La evidencia empírica acumulada al momento es contradictoria y no concluyente. En los pocos estudios sobre responsabilidad social empresarial que han realizado comparaciones de género se ha encontrado que las mujeres están ligeramente más inclinadas a considerar el modelo de grupos de interés, siendo más susceptibles a las necesidades de otros que los hombres (Arlow, 1991; Lämsä, 2008).

En resumen, es importante proveer a los estudiantes de las escuelas de negocios herramientas nuevas y relevantes que les permitan afrontar los diversos y complejos conflictos éticos con los que 
se enfrentarán en su carrera profesional. El razonamiento bioético puede aportar al entendimiento y a la solución de muchos conflictos éticos en el ámbito de los negocios. De igual forma, es necesario que los estudiantes adquieran conciencia de la responsabilidad social de las empresas. Por lo tanto, existe la necesidad de reconocer el espacio común a nivel teórico entre la responsabilidad social empresarial y la bioética y su incorporación al currículo de administración de empresas. De igual forma, hay la necesidad de crear instrumentos de medición confiables que determinen la orientación hacia la responsabilidad social empresarial y el razonamiento bioético de los estudiantes de administración de empresas, que permita atemperar el currículo a la realidad histórica actual.

\section{Objetivos}

En esa dirección, el propósito principal de este estudio es examinar si existe una relación entre la responsabilidad social empresarial y el razonamiento bioético utilizando como marco conceptual el modelo multidimensional de las empresas propuesto por Carroll (1979) y los principios bioéticos propuestos por Beauchamp y Childress (1979), y desarrollar instrumentos de medición confiables para ambos constructos. Los objetivos específicos son:

1. Determinar la importancia de los principios bioéticos en la definición de lo que constituye una empresa.

2. Determinar la validez de las cuatro dimensiones del modelo de Carroll (1979) y su importancia relativa.

3. Calcular índices para medir la orientación hacia la responsabilidad social empresarial y cada una de las cuatro dimensiones teóricas.

4. Calcular índices de razonamiento bioético y determinar su efecto en los índices de las cuatro dimensiones de la empresa.

5. Determinar las características que deben tener las empresas para ser consideradas exitosas, socialmente responsables y el efecto de los principios bioéticos para lograrlo.

6. Identificar posibles diferencias en las respuestas debido al género o nivel educativo. 


\section{IMPORTANCIA DEL EsTUDIO}

Este estudio contribuye a la investigación de la ética de varias maneras. Si bien no es el primero en plantear la utilidad de los principios bioéticos para examinar situaciones propias de los negocios, sí es el primero en establecer de forma cuantitativa la relación entre los principios bioéticos y la responsabilidad social empresarial. Este estudio es el primero en desarrollar un instrumento de medición capaz de medir de forma confiable un índice de orientación hacia la responsabilidad social empresarial y de sus cuatro dimensiones teóricas, identificando a su vez los factores que explican dicha orientación. Además, es el primero en desarrollar un instrumento de medición para medir el razonamiento bioético de los individuos y cómo éste afecta su orientación hacia la responsabilidad social empresarial. Por último, aporta nueva evidencia sobre las diferencias en el razonamiento ético debido al género y el nivel educativo.

Los resultados obtenidos en este estudio tienen implicaciones prácticas importantes. Por ejemplo, proveen un nuevo enfoque para el diseño de programas de adiestramiento ético en las instituciones educativas, las empresas y las agencias gubernamentales. Los mismos plantean la importancia de desarrollar y fortalecer la capacidad de los estudiantes (futuros contadores, administradores y profesionales) para lidiar con las presiones del entorno. Este estudio identifica la deseabilidad de incluir el razonamiento bioético y la responsabilidad social empresarial, en la enseñanza e integración de la ética en el currículo de las escuelas de negocio.

\section{ReVisión de Literatura}

\section{BIOÉTICA}

Van Rensselaer Potter utilizó el término por primera vez en 1970 en un artículo y en el 1971 publica el libro Bioética: Puente hacia el futuro en el cual se recogen varios de sus artículos. Desde entonces, muchos estudiosos han aportado nuevas concepciones, métodos y justificaciones (Santos y Vargas, 2006). No hay consenso en cuanto al dominio apropiado para la aplicación de la ética en temas biológicos. Algunos autores lo reducen a lo rela- 
cionado con el tratamiento médico y los avances tecnológicos, mientras que otros le otorgan un sentido más amplio, incluyendo todo aquello que afecte a los organismos. El criterio ético fundamental que regula esta disciplina es el respeto al ser humano y su dignidad.

El descubrimiento de los experimentos médicos con los prisioneros en los campos de concentración de la Alemania nazi y otras investigaciones con procedimientos poco o dudosamente éticos, como las prácticas del Hospital Judío de Enfermedades Crónicas (Brooklyn, 1963) o la Escuela de Willowbrook (Nueva York, 1963) y el Estudio de Sífilis de la Universidad de Tuskegee (1972), van creando la necesidad de regulación, o al menos, declaraciones a favor de las víctimas de estos experimentos. Las primeras declaraciones de bioética surgen de los esfuerzos para regular la investigación y la experimentación médica, tales como, el Código de Nuremberg (1947), la Declaración de Helsinki (1964) y el Informe Belmont (1979).

En 1979, los bioeticistas T. L. Beauchamp y J.F. Childress definieron los cuatro principios de la bioética —autonomía, no maleficencia, beneficencia y justicia- en el libro Principles of bioethical ethics del cual fue publicada la quinta edición en el 2001. Beauchamp (2007) explica que el principio de autonomía tiene sus raíces en la moral liberal y la tradición política en las cuales es importante la libertad y el derecho de elegir de los individuos. El autor argumenta que la autonomía es cuando la persona tiene un entendimiento adecuado que le permite gobernarse a sí misma libre de restricciones externas o limitaciones personales que se lo impidan, lo que le permite actuar de acuerdo al plan personal que elija. Por lo tanto, respetar la autonomía de las personas implica reconocer y valorar las capacidades y posturas de los individuos, incluyendo su derecho a tener sus propias opiniones, tomar sus propias decisiones y actuar de acuerdo a sus valores y creencias (Beauchamp, 2007). Este principio supone que los individuos autónomos tienen derecho a tomar sus propias decisiones sin restricciones de otros, pero a su vez los otros están obligados a propiciar y facilitar el que los individuos tomen sus propias decisiones. En el ámbito médico, el consentimiento es la máxima expresión de este principio, constituyendo un derecho del paciente y un deber del médico. 
El principio de no maleficencia se refiere a abstenerse de realizar acciones que puedan causar daño o perjudicar a otros. Este es un imperativo ético válido no sólo en el ámbito biomédico, sino en el que se basan muchas reglas básicas de la moral común, como no matar, no causar dolor, no romper promesas, etcétera (Beauchamp, 2007). En el ámbito de la salud, sin embargo, este principio debe encontrar una interpretación adecuada, pues a veces las acciones médicas dañan para obtener un bien. Entonces, sería más propio decir que de lo que se trata es de no perjudicar innecesariamente a otros. El análisis de este principio está íntimamente relacionado con el de beneficencia, de forma tal que prevalezca el beneficio sobre el perjuicio.

La beneficencia es la obligación de actuar en beneficio de otros, promoviendo sus legítimos intereses y suprimiendo perjuicios. Este principio requiere que se maximicen los beneficios y se minimicen los posibles daños, y que se balanceen los beneficios contra los riesgos. Una de las motivaciones para separar la no maleficencia de la beneficencia es que estos principios pueden entrar en conflicto, requiriendo que se sopesen según la situación no habiendo una forma mecánica de establecer la importancia de los mismos (Beauchamp, 2007). El autor destaca que es difícil determinar que se requiere o no se requiere para cumplir con el principio sin ponerlo en el contexto particular, pero sí existe la obligación de actuar en beneficio de otros.

El principio de la justicia destaca que se debe tratar a cada uno como corresponda, con la finalidad de disminuir las situaciones de desigualdad (ideológica, social, cultural, económica, etcétera). El mismo puede dividirse en dos: un principio formal (tratar igual a los iguales y desigual a los desiguales) y un principio material (determinar las características relevantes para la distribución de los recursos y las cargas). Por ejemplo, en la investigación médica es importante determinar cómo distribuir justamente los riesgos y los beneficios que puedan resultar de la misma, tratando de proteger a las poblaciones más vulnerables.

Beauchamp (2007) argumenta que este marco conceptual de cuatro principios provee una guía general para resolver los conflictos éticos que puedan surgir en el campo de la medicina. No obstante, eso no implica que los mismos sean absolutos. Todos los principios generales tienen excepciones y tanto las conclusiones morales que 
de ellos se derivan como los propios principios siempre están sujetos a modificaciones y reformulaciones. Mediante este proceso los principios adquieren valor práctico.

\section{RESPONSABILIDAD SOCIAL EMPRESARIAL}

La Unión Europea define la Responsabilidad Social Empresarial (RSE) como la integración voluntaria, por parte de las empresas, de las preocupaciones sociales y medioambientales en sus operaciones comerciales y sus relaciones con sus interlocutores. Di Biase De Lillo (2005) argumenta que los principales ámbitos que se trabajan sobre la RSE en las empresas, son los principios éticos, calidad de vida laboral, medio ambiente, compromiso con la comunidad y marketing responsable. Kliskberg (2010) reclama que la agenda de RSE para América Latina debe enfocarse en la transparencia del gobierno corporativo, buenas políticas de personal, juego limpio con el consumidor, políticas "pro-verde" en cuestiones ambientales, códigos de ética aplicables de igual forma en países desarrollados y no desarrollados y compromiso social. En Porter y Kramer (2006) los autores resaltan la importancia estratégica de la RSE para hacer a las empresas más competitivas, pero en Porter y Kramer (2011) proponen que la RSE debe ser reemplazada por un nuevo concepto: creación de valor compartido (Creating Shared Value), planteando que el objetivo de las empresas debe ser crear valor compartido con la sociedad. Vives (2011) plantea en respuesta a esta nueva propuesta que lo que proponen los autores es el concepto estratégico de las prácticas responsables propulsado por la RSE, lo cual no es innovador y, por el contrario, añade más confusión de términos.

A pesar de que la responsabilidad social empresarial ha generado una extensa bibliografía en los círculos empresariales y académicos, en los últimos años sigue habiendo mucha confusión conceptual y terminológica. La RSE se ha convertido en una especie de sombrilla gigante en la que tienen cabida multiplicidad de conceptos y estrategias. No obstante, más allá de la cuestión terminológica y de las diversas teorizaciones que van asociadas a la RSE, todas las partes coinciden en que es un nuevo paradigma de comportamiento de las grandes corporaciones, resultado de una adaptación empresarial a 
los cambios sociales surgidos en el marco de la globalización económica (Ramiro y Pulido, 2009).

Con esta nueva perspectiva, se pretende cambiar el esquema tradicional del negocio orientado exclusivamente hacia la maximización del valor de la empresa y dirigido únicamente a los accionistas (shareholders), por un modelo que toma en consideración a otras partes de la sociedad. La visión centrada en los accionistas plantea que la función de las empresas es proporcionar bienes y servicios que lleven a la maximización de los beneficios a corto plazo y no reconoce ninguna responsabilidad social más allá de la obligación de maximizar el valor para el accionista (Friedman, 1970; Heath y Norman, 2004). En contraste, la teoría de los grupos de interés (stakeholders) plantea que las empresas no pueden ignorar el contexto en el que operan puesto que están interconectadas a una red de relaciones con un gran número de individuos e instituciones denominadas grupos de interés o stakeholders (Freeman, 1984; Donaldson y Preston, 1995; Clarkson, 1995). Se rechaza la idea de que una corporación sólo es responsable ante sus accionistas, argumentando que los intereses de otros grupos son también válidos y merecen ser atendidos

Freeman (1984) define a los stakeholders como cualquier grupo o individuo que puede afectar o ser afectado por las actividades de las empresas. En las investigaciones sobre los stakeholders se siguen identificando aquellos individuos o entidades que deben ser considerados como grupos de interés, los cuales han ido en aumento, y examinando las relaciones entre ellos. También, los investigadores han dedicado un considerable esfuerzo en determinar las ventajas que supone para las empresas adoptar la RSE. Por ejemplo, Post, Preston y Sachs (2002) afirman que la capacidad de una empresa para generar riqueza sostenible y, por tanto, valor a largo plazo, está determinada por sus relaciones con los stakeholders claves. De acuerdo con Freeman y Velamuri (2006), la supervivencia y rentabilidad a largo plazo de las empresas dependen del mantenimiento de una cooperación efectiva con los grupos de interés de forma continua.

A finales de los años 70, Carroll (1979) definió la responsabilidad social corporativa como las expectativas económicas, legales, éticas y discrecionales que la sociedad tiene sobre la organización, lo que 
implícitamente recoge la responsabilidad de las empresas hacia diversos actores sociales, afín con la teoría de los grupos de interés. Las responsabilidades económicas se refieren a la obligación de las empresas de ser productivas y lucrativas para satisfacer las demandas de consumo de la sociedad. Las obligaciones legales destacan que las responsabilidades económicas tienen que cumplirse dentro del marco jurídico y legal vigente. Las responsabilidades éticas se refieren a aquellas normas, códigos y normas sociales no escritas que las empresas deben acatar. La dimensión discrecional se refiere a aquellas obligaciones, particularmente filantrópicas, que las empresas asumen voluntariamente. Carroll (1991) argumenta que estos cuatro componentes atienden el espectro completo de obligaciones que los negocios tienen con la sociedad. Este modelo se enfoca en el tipo de obligaciones que las empresas adquieren, a diferencia de la teoría de los grupos de interés, la cual se enfoca en identificar las necesidades y reclamos de los grupos implicados.

No obstante, ambos marcos teóricos son afines para definir el rol de las empresas en la sociedad. Ambos modelos reconocen la dimensión económica de las empresas y el interés de los accionistas; pero, a diferencia de la ideología tradicional, argumentan que esa no es la única dimensión o función de las empresas. Carroll (1979) argumenta que las empresas adquieren, además, obligaciones legales, éticas y de libre discreción. Este argumento es cónsono con la premisa de la teoría de los grupos de interés de que las empresas tienen que satisfacer las demandas de los diversos grupos con los que interaccionan. Los reclamos de estos grupos pueden ser de carácter legal, ético o social.

Aupperle y otros (1985) desarrollaron un instrumento de respuesta forzada para medir los grados de orientación hacia la responsabilidad social empresarial basado en el marco teórico provisto por Carroll (1979). Los resultados de los estudios que han utilizado esta escala tienden a confirmar las cuatro dimensiones teóricas y su jerarquía; la más importante corresponde a la dimensión económica, seguida de la legal, la ética y la de libre discreción (Aupperle y Simmons, 1989; Ibrahim y Angeldis, 1995; Oneill, 1989; Pinkston y Carroll, 1996; Burton, 2000). No obstante, Aupperle y otros (1985) encontraron una relación inversa entre la dimensión económica y ética, implicando que ambas son mutuamente excluyentes. 
Otros estudios han encontrado diferencias entre grupos. Burton y Hegarty (1999) encontraron que los gerentes practicantes tenían estándares éticos ligeramente más altos y más conciencia sobre la responsabilidad social corporativa que los estudiantes de negocios. En contraposición, Ibrahim y Angeldis (1993) encontraron que los estudiantes de negocios están más orientados a las dimensiones éticas y discrecionales y menos a la económica, que los ejecutivos. Resultados similares fueron obtenidos comparando estudiantes de contabilidad y contadores practicantes (Ibrahim, 2006). Angeldis e Ibrahim (2004) e Ibrahim y Angeldis (2008) encontraron que estudiantes de negocios religiosos estaban más orientados al aspecto ético y menos al desempeño económico que los estudiantes menos religiosos.

\section{Relación entre la Bió́tica y la Responsabilidad Social EMPResarial}

Si bien los principios bioéticos están dirigidos a personas, los mismos pueden ser aplicados a las empresas teniendo en cuenta que éstas son personas organizadas en sistemas orgánicos y que las mismas, al igual que los humanos, son responsables por lo que hacen, dejan de hacer o dejan hacer. El eje principal de la bioética clínica es la relación médico-paciente dirigida a proteger a la parte más vulnerable, que normalmente es el paciente. En la arena de los negocios hay múltiples actores unidos por variadas relaciones siendo unos más vulnerables que otros. No obstante, el reto es el mismo: lograr que las relaciones entre dos entes sean éticas.

En el ámbito de los negocios, es necesario ampliar el concepto de autonomía a las organizaciones. Las empresas, como entes jurídicos, tienen entonces el derecho de perseguir sus propios intereses, pero de igual forma están obligadas a respetar los intereses de aquellos grupos a los que puedan afectar con sus actividades, sean personas naturales o entes jurídicos. Por ejemplo, en la relación de productor y consumidor, el primero debe proveer toda la información relevante para que el segundo tome una decisión informada respecto a comprar o no el producto (Fisher, 2001). Argumentos similares podrían presentarse en los casos de las relaciones entre patronos y empleados, compradores y suplidores y hasta en las relaciones con la competencia. No obstante, es importante notar que el ejercicio de 
la autonomía se hace en un contexto social, por lo que la autonomía de unos está restringida por la autonomía de los otros. Por lo tanto, es igualmente importante ejercer la autonomía propia y respetar la de los demás, así como propiciar el que los otros ejerzan la propia. Es importante destacar que la mayoría de las transacciones comerciales deben ser precisamente contratos entre entes autónomos en los que se supone que ambas partes persiguen sus propios intereses, respetando los ajenos.

El principio de no maleficencia aplica en el campo de la medicina porque en la relación médico-paciente hay una parte con la capacidad de infringir daño, aun cuando no sea intencional, y hay otra parte propensa a sufrir daño con menos capacidad para defenderse del mismo. En las actividades médicas, normalmente, el posible daño está limitado a una persona y sus allegados o, en el peor de los casos, a un grupo limitado de individuos, como en el caso de investigaciones de dudosa justificación ética. En las actividades comerciales, una empresa tiene la capacidad potencial de causarle daños a miles de individuos, simultáneamente. Los daños pueden ser desde económicos, como sucedió con los grandes escándalos de principios de siglo, hasta causar la muerte sea por productos defectuosos, condiciones laborales inadecuadas o contaminación ambiental. Los daños podrían ser tan devastadores que podrían afectar a generaciones aún no nacidas, como podría ser el caso de la contaminación de cuerpos de agua o de terrenos. Por lo tanto, teniendo las empresas la capacidad de causar daños tan diversos a tan diversos grupos, y siendo estos vulnerables a sufrirlos, resulta clara la obligación de las empresas de no causar daños. De hecho, muchas de estas obligaciones hacia diversos grupos están codificadas legalmente, tales como las leyes de protección al consumidor, seguridad e higiene en el trabajo, o protección ambiental (De la Cruz y Cabrera, 2007).

De la misma forma que una empresa puede causar daños a muchos individuos, también tiene la capacidad de beneficiarlos y de tal capacidad surge su obligación. Posiblemente, la obligación de beneficencia más clara, por su larga tradición, es la que tienen los directivos de las empresas como agentes fiduciarios con los accionistas. No obstante, dado que las empresas no operan en el vacío y son parte integral de la sociedad, tienen la misma obligación de hacerles 
el bien a otros que tienen todos los ciudadanos en su carácter individual. Estas obligaciones van desde producir productos seguros hasta cumplir con las obligaciones contractuales que contraigan. Las mismas incluyen, además, envolverse en actividades que promuevan una mejor calidad de vida de la comunidad circundante y de la sociedad en general.

Uno de los grandes retos de la humanidad es distribuir los beneficios y las cargas entre todos sus constituyentes. La justicia exige mínimamente que los iguales sean tratados igual y los desiguales, desigual de acuerdo con el criterio de diferenciación que se elija. Las empresas poseen y manejan recursos diversos, por lo que su distribución debe ser justa. En las relaciones laborales no debería haber discriminación en el reclutamiento o en la promoción del personal contra diversos grupos como históricamente ha ocurrido contra las mujeres y los homosexuales, pero sí debería haber discriminación para proteger a los menores. La paga por igual trabajo debería ser la misma en cualquier lugar, porque de otro modo se están beneficiando los consumidores de un país a expensas de la imposición de cargas mayores a los empleados de otro país. El lucro desmedido, la contaminación ambiental y la competencia desleal son algunos conflictos éticos en el área de los negocios que podrían ser analizados a la luz del principio de justicia.

\section{Metodología}

\section{INSTRUMENTO}

El cuestionario consta de ocho partes. El mismo está basado en el instrumento desarrollado por Aupperle (1985), pero con distinta metodología. En vez de utilizar el formato de opción forzada, se optó por utilizar una escala numérica continua en la que los participantes expresan su respuesta en términos porcentuales. Esta escala captura la importancia que los participantes le adscriben a cada premisa en términos absolutos en vez de relativos.

La primera sección incluye 25 premisas de objetivos, prácticas y políticas para que los participantes indiquen si las mismas son importantes para que la empresa cumpla con su razón de ser. Siguiendo el 
modelo de Carroll (1979), se incluyeron premisas de cada una de las cuatro dimensiones de las empresas: cinco de la función económica, seis premisas de la función legal, cinco de la ética, cinco de la de libre discreción y cuatro del razonamiento bioético. Las premisas de libre discreción se enfocaron en actividades sociales diversas, en vez de estrictamente filantrópicas. La segunda sección incluye 10 premisas para que los participantes indiquen la importancia de diversas funciones de los directivos. Al igual que en la pregunta anterior, se incluyen premisas relacionadas con las cuatro dimensiones de las empresas y otras del razonamiento bioético.

Desde la sección III hasta la VI se presentan varias premisas de cada una de las dimensiones teóricas de las empresas en las que los participantes indican su acuerdo. Estas cuatro secciones permiten capturar la importancia que los participantes les otorgan a cada una de las dimensiones y las razones para así hacerlo, lo cual representa un avance respecto a los estudios previos. La sección VII incluye 15 premisas de características de cada una de las dimensiones de la empresa y del razonamiento bioético para que los participantes indiquen cuáles y cuánto son necesarias las mismas para ser una empresa exitosa y para ser una empresa socialmente responsable. Esta pregunta permite capturar la opinión de los participantes sobre si la responsabilidad social empresarial tiene algún impacto en el éxito de la empresa. La última sección incluye seis preguntas de información demográfica.

\section{Pruebas Estadísticas}

Se realizó un análisis factorial para determinar la existencia de las cuatro dimensiones teóricas de las empresas y si el razonamiento bioético es una dimensión relacionada. Además, se determinó un índice de orientación hacia la responsabilidad social empresarial y el razonamiento bioético calculando el promedio de las respuestas a la primera pregunta y a las premisas específicas de los principios bioéticos. Desde la pregunta III hasta la VI se determinaron índices de orientación hacia cada una de las dimensiones teóricas examinadas y un índice de orientación bioética sumando las respuestas a las premisas que indicaban una mayor orientación hacia la dimensión exa- 
minada y restándole las respuestas a las premisas que la disminuían. Luego, se convirtieron a una escala porcentual para comparar y simplificar su análisis. En la última pregunta se compararon los promedios de las respuestas mediante pruebas paired $t$ - test para identificar diferencias significativas. Se calcularon coeficientes Chronbach's Alpha para determinar la confiabilidad del instrumento. Además, se realizaron pruebas Whitney U para identificar diferencias significativas en las respuestas debido al género y al nivel educativo de los participantes.

\section{Resultados}

\section{Composición de la Muestra}

La muestra total consistió de 175 estudiantes de la Facultad de Administración de Empresas. Poco más de una tercera parte (38\%) son hombres, mayoritariamente de nivel subgraduado $(77 \%)$ y menor de 25 años (82\%). Más de la mitad de ellos (64\%) estudian Contabilidad (34\%), Finanzas (20\%) o Mercadeo (10\%). Más de la mitad de este grupo ha tomado un curso de Ética Empresarial (30\%) o lo estaba tomando en el momento en que contestó la encuesta (31\%).

\section{Índice de Orientación hacia la Responsabilidad Empresarial}

La Tabla 1 presenta el promedio obtenido en las premisas que se utilizaron para definir las dimensiones de la empresa, según el modelo de Carroll (1979) y el razonamiento bioético. Se presentan, además, los coeficientes Cronbach's Alpha de cada una de las dimensiones teóricas. Los coeficientes resultaron en valores entre .62 y .91. Esto refleja una confiabilidad aceptable para un estudio exploratorio, y la mayoría de ellos exceden el límite de .70 generalmente aceptado y defendido por Nunally and Bernstein (1994) como el mínimo deseable. El coeficiente de la dimensión ética resultó originalmente en .63 , pero aumentaba a .75 si se eliminaba la premisa operar de forma ética sin sacrificar las metas económicas, lo que en efecto se hizo de los análisis subsiguientes. Ninguno de los otros coeficientes mejoraba significativamente con la eliminación de alguna premisa. 
Tabla 1 - Dimensiones Teóricas de las Empresas

\begin{tabular}{|c|c|c|c|}
\hline Premisas & Promedio & $\begin{array}{l}\text { Desviación } \\
\text { Estándard }\end{array}$ & $\begin{array}{c}\text { Coeficiente } \\
\text { Chronbach } \\
\text { Alpha }\end{array}$ \\
\hline Dimensión Económica & 85.60 & 13.53 & .69 \\
\hline Operar eficientemente. & 96.91 & 9.31 & \\
\hline Ser competitivas. & 89.10 & 18.25 & \\
\hline Producir riqueza. & 82.19 & 22.37 & \\
\hline Ser lucrativas. & 81.16 & 23.93 & \\
\hline Maximizar la ganancia de los accionistas. & 78.61 & 23.48 & \\
\hline Dimensión Legal & 93.59 & 10.24 & .79 \\
\hline Cumplir con las leyes ambientales. & 95.66 & 12.73 & \\
\hline Cumplir con los contratos según las normas legales vigentes. & 95.44 & 11.68 & \\
\hline Contratar y compensar al personal según la ley. & 94.92 & 14.24 & \\
\hline Pagar impuestos según la ley. & 94.31 & 14.36 & \\
\hline $\begin{array}{l}\text { Producir bienes y servicios según los estándares } \\
\text { requeridos por ley. }\end{array}$ & 93.64 & 14.56 & \\
\hline Acatar las leyes que regulan la libre competencia. & 87.80 & 18.69 & \\
\hline Dimensión Ética & 90.30 & 12.97 & .75 \\
\hline Fomentar conductas éticas entre sus constituyentes. & 95.17 & 10.49 & \\
\hline Actuar de acuerdo a las normas éticas de la sociedad. & 92.00 & 15.30 & \\
\hline Ser reconocida como una empresa ética. & 91.83 & 18.53 & \\
\hline Operar de forma ética sin sacrificar las metas económicas. & 83.50 & 28.33 & Eliminada \\
\hline $\begin{array}{l}\text { Operar de forma ética, aunque se sacrifiquen } \\
\text { las metas económicas. }\end{array}$ & 82.30 & 22.32 & \\
\hline Dimensión de Libre Discreción & 84.72 & 16.70 & .86 \\
\hline Ser reconocida como una empresa socialmente responsable. & 93.07 & 15.53 & \\
\hline Mejorar la calidad de vida de la sociedad. & 86.50 & 19.98 & \\
\hline Mejorar la calidad de vida de su comunidad circundante. & 85.78 & 21.44 & \\
\hline Ayudar a resolver problemas sociales. & 85.69 & 18.21 & \\
\hline Destinar parte de las ganancias a actividades benéficas. & 72.83 & 26.84 & \\
\hline Índice Razonamiento Bioético General & 88.50 & 12.93 & .62 \\
\hline $\begin{array}{l}\text { Evitar que sus operaciones causen cualquier } \\
\text { tipo de daños a otros. }\end{array}$ & 95.84 & 11.82 & \\
\hline Actuar de forma justa en sus operaciones y actividades. & 94.74 & 13.70 & \\
\hline $\begin{array}{l}\text { Establecer relaciones con entidades basadas } \\
\text { en el respeto mutuo. }\end{array}$ & 86.98 & 19.33 & \\
\hline $\begin{array}{l}\text { Beneficiar con sus operaciones y actividades } \\
\text { a diversos grupos. }\end{array}$ & 83.24 & 21.72 & \\
\hline Promedio Índice Orientación RSE & 88.66 & 10.34 & .91 \\
\hline
\end{tabular}


Los promedios más altos se obtuvieron mayoritariamente en la dimensión legal y en la dimensión ética; esto implica que los participantes le otorgan mucha importancia al cumplimiento de la ley y de las normas éticas. Los participantes le otorgaron menos importancia a la dimensión de libre discreción y a la económica, y mayor importancia a la legal y a la ética. No obstante, es importante notar que los promedios de todas las dimensiones, el de la dimensión de razonamiento bioético y el índice de orientación hacia la responsabilidad social empresarial sobrepasan el $80 \%$ de importancia. Este hallazgo es indicativo de que los participantes entienden que las empresas son organizaciones con múltiples funciones, todas importantes, y no un mero ente económico.

\section{AnÁLISIS FACTORIAL}

Antes de proceder al análisis factorial se determinó la adecuacidad del procedimiento mediante las pruebas Kaiser-Myer-Olkin y Bartlett's Test of Sphericity. La primera prueba arrojó un resultado de .875 y la segunda resultó con un nivel de significancia de .000 , por lo que se concluyó que la muestra es muy adecuada para realizar el procedimiento. Se estableció el valor de .50 para incluir un elemento en un factor y un eigenvalue de 1.00 para retener el factor. Todos los coeficientes resultaron estar asociados significativamente a un solo factor y todos los factores tienen eigenvalues mayores de uno.

El procedimiento resultó en una solución de 5 factores, ligeramente diferente a los cinco identificados teóricamente. Los factores explican casi un $65 \%$ del fenómeno, lo cual es muy bueno en este tipo de estudios. Los coeficientes de confiabilidad de cada factor fluctuaron entre .71 y .91 los cuales reflejan una gran confiabilidad. El primer factor está compuesto por todas las premisas de la dimensión de libre discreción, dos bioéticas y dos éticas, y explica casi un $40 \%$ del fenómeno. Esto implica que los participantes reconocen la función social de las empresas como una dimensión separada y, además, la más importante. Las premisas bioéticas incluidas en este factor le añaden mayor sentido a la dimensión social, al tratarse de una que beneficia a diversos grupos con los que la empresa debe es- 
tablecer relaciones, lo que las lleva a ser reconocidas como empresas socialmente responsables y éticas.

El segundo factor es el más híbrido. Incluye dos premisas legales, una ética, una bioética y otra económica. Tomadas en conjunto, esta dimensión parece explicar una función de acoplamiento social, más que de cumplimiento legal. Las premisas más importantes se refieren a obligaciones legales con la competencia y con el personal, seguidas de actuar de acuerdo con las normas éticas de la sociedad y de forma justa, y operar eficientemente. Podría decirse que, a los ojos de los participantes, las empresas están obligadas a seguir "las reglas del juego" en términos generales en el contexto en el que operan, lo cual las hará eficientes. Los participantes parecen conferirle a la eficiencia una connotación más bien funcional o la confunden con la efectividad. No parece que la entiendan como un balance entre beneficios y costos.

Tabla 2 - Resultados del Análisis Factorial

\begin{tabular}{|c|c|c|c|}
\hline Premisas & $\begin{array}{l}\text { Coeficiente de } \\
\text { Correlación }\end{array}$ & Varianza & $\begin{array}{c}\text { Coeficiente } \\
\text { Chronbach's } \\
\text { Alpha }\end{array}$ \\
\hline Factor 1 - Dimensión Social & & 38.22 & 89.7 \\
\hline Mejorar la calidad de vida de la sociedad. & .832 & & \\
\hline $\begin{array}{l}\text { Mejorar la calidad de vida de su comunidad } \\
\text { circundante. }\end{array}$ & .797 & & \\
\hline $\begin{array}{l}\text { Destinar parte de las ganancias a } \\
\text { actividades benéficas. }\end{array}$ & .776 & & \\
\hline Ayudar a resolver problemas sociales. & .757 & & \\
\hline $\begin{array}{l}\text { Beneficiar con sus operaciones y } \\
\text { actividades a diversos grupos. }\end{array}$ & .743 & & \\
\hline $\begin{array}{l}\text { Ser reconocida como una empresa } \\
\text { socialmente responsable. }\end{array}$ & .707 & & \\
\hline Ser reconocida como una empresa ética. & .573 & & \\
\hline $\begin{array}{l}\text { Establecer relaciones con entidades, } \\
\text { basadas en el respeto mutuo. }\end{array}$ & .571 & & \\
\hline $\begin{array}{l}\text { Operar de forma ética, aunque se } \\
\text { sacrifiquen las metas económicas. }\end{array}$ & .471 & & \\
\hline
\end{tabular}




\begin{tabular}{|c|c|c|c|}
\hline Factor 2 - Acoplamiento Social & & 10.03 & 81.9 \\
\hline $\begin{array}{l}\text { Acatar las leyes que regulan la libre } \\
\text { competencia. }\end{array}$ & .741 & & \\
\hline $\begin{array}{l}\text { Contratar y compensar al personal según } \\
\text { la ley. }\end{array}$ & .723 & & \\
\hline $\begin{array}{l}\text { Actuar de acuerdo a las normas éticas de la } \\
\text { sociedad. }\end{array}$ & .671 & & \\
\hline $\begin{array}{l}\text { Actuar de forma justa en sus operaciones y } \\
\text { actividades. }\end{array}$ & .663 & & \\
\hline Operar eficientemente. & .545 & & \\
\hline Factor 3 - Dimensión Legal & & 7.03 & 83.2 \\
\hline $\begin{array}{l}\text { Cumplir con los contratos según las normas } \\
\text { legales vigentes. }\end{array}$ & .794 & & \\
\hline $\begin{array}{l}\text { Evitar que sus operaciones causen cualquier } \\
\text { tipo de daños a otros. }\end{array}$ & .674 & & \\
\hline $\begin{array}{l}\text { Fomentar conductas éticas entre sus } \\
\text { constituyentes. }\end{array}$ & 631 & & \\
\hline Pagar impuestos según la ley. & .593 & & \\
\hline Cumplir con las leyes ambientales. & .590 & & \\
\hline $\begin{array}{l}\text { Producir bienes y servicios según los } \\
\text { estándares requeridos por ley. }\end{array}$ & .554 & & \\
\hline $\begin{array}{c}\text { Factor } 4 \text { - Dimensión Efectividad } \\
\text { Económica }\end{array}$ & & 4.73 & .705 \\
\hline Ser lucrativas. & .848 & & \\
\hline Producir riqueza. & .720 & & \\
\hline Ser competitivas. & .682 & & \\
\hline $\begin{array}{c}\text { Factor } 5 \text { - Dimensión Eficiencia } \\
\text { Económica }\end{array}$ & & 4.50 & \\
\hline Maximizar la ganancia de los accionistas. & .750 & & \\
\hline Total & & 64.50 & 91.11 \\
\hline
\end{tabular}

El tercer factor incluye mayoritariamente premisas de la dimensión legal junto a una ética y otra bioética. Las legales incluyen cumplir con los contratos y las leyes ambientales, pagar impuestos y producir los bienes y servicios de acuerdo a la ley. Parecería que los participantes visualizan el cumplimiento de la ley como una forma de evitar causarles daños a otros y a su vez entienden que dicho cumplimiento es ético, por lo que es importante que se fomente el que se cumplan. 
El cuarto factor está compuesto de tres premisas estrictamente económicas relacionadas con ser efectivos en ese aspecto: ser lucrativos, producir riqueza y ser competitivos. El último factor incluye otra premisa económica sola: maximizar la ganancia de los accionistas. Resulta interesante la separación que realizaron de estos conceptos claramente económicos. Una posible explicación es que mientras las primeras tres premisas consisten en ser efectivos, la última, en tanto está relacionada con la maximización; implica lograr ser eficientes y los participantes se conforman con un nivel de ejecución inferior al máximo.

\section{Funciones de los Directivos}

La Tabla 3 presenta el promedio obtenido en las premisas relacionadas con las funciones de los directivos. Todas las funciones presentadas obtuvieron promedios sobre $80 \%$, excepto el resolver problemas sociales. Estos resultados reflejan varias contradicciones vinculadas a las respuestas de la pregunta anterior. Por un lado la dimensión social es la función más importante de las empresas, pero resolver problemas sociales es la función menos importante de los directivos, y las relaciones con los diversos grupos de interés son menos importantes.

Sin embargo, dado la forma general en la que están redactadas las premisas en esta pregunta, las cuatro funciones primarias de los directivos guardan cierto parecido con el factor de la dimensión del acoplamiento social. La única premisa de razonamiento bioético incluida en las primeras cuatro funciones es tomar decisiones justas. Es importante notar que la justicia es una filosofía moral presente en muchas disciplinas, por lo que no se puede interpretar como un razonamiento estrictamente bioético. No obstante, todas las demás premisas resultaron con porcentajes relativamente altos, lo que señala una vez más que el razonamiento bioético tiene cabida en el escenario empresarial. 
EL RAZONAMIENTO BIOÉTICO Y LA ORIENTACIÓN HACIA RESPONSABILIDAD SOCIAL...

Tabla 3 - Funciones de los Directivos

\begin{tabular}{lcc}
\hline \multicolumn{1}{c}{ Premisas } & Promedio & $\begin{array}{c}\text { Desviación } \\
\text { Estándar }\end{array}$ \\
\hline Cumplir con todas las leyes y normativas vigentes. & 96.33 & 10.18 \\
Operar de forma ética. & 96.12 & 12.12 \\
Tomar decisiones justas. & 94.63 & 15.55 \\
Lograr las metas económicas de la organización. & 93.89 & 13.66 \\
$\begin{array}{l}\text { Evitar daños a otros con sus acciones u omisiones. } \\
\text { Procurar el mejoramiento de los constituyentes de la } \\
\text { empresa. }\end{array}$ & 93.24 & 15.72 \\
$\begin{array}{l}\text { Respetar el derecho de diversos grupos a elegir y procurar } \\
\text { sus intereses. }\end{array}$ & 89.89 & 16.29 \\
$\begin{array}{l}\text { Defender derecho de la empresa a elegir y perseguir sus } \\
\text { propios intereses. }\end{array}$ & 85.45 & 19.49 \\
$\begin{array}{l}\text { Procurar el mejoramiento de grupos externos a la empresa. } \\
\text { Resolver problemas sociales. }\end{array}$ & 80.52 & 21.25 \\
\hline
\end{tabular}

\section{Í́NDICES DE ORIENTACIÓN HACIA CADA DIMENSIÓN DE LA EMPRESA}

\section{Índice de ORIentación EConómica}

La Tabla 4 muestra los resultados obtenidos en la pregunta específica de la dimensión económica. Se les solicitó a los participantes que expresaran su acuerdo en términos porcentuales con la premisa: las metas económicas de la empresa deben lograrse, sujeto a 13 condiciones tales como cumpliendo con la ley, respetando los derechos de otros, etcétera. 
Tabla 4 - Índice de Orientación Económica

\begin{tabular}{lcc}
\hline \multicolumn{1}{c}{ Premisas } & Promedio & $\begin{array}{c}\text { Desviación } \\
\text { Estándar }\end{array}$ \\
\hline Respetando los derechos de los otros. & 95.09 & 15.60 \\
Siendo justos. & 94.87 & 13.67 \\
Operando éticamente. & 94.42 & 14.06 \\
Sin hacerle daño a otros. & 94.26 & 17.62 \\
Cumpliendo con todas las leyes aplicables. & 93.88 & 16.21 \\
Haciendo algún bien social. & 84.41 & 23.47 \\
Sin importar los medios para lograrlo. & 29.89 & 35.85 \\
Aunque no se haga ningún bien social. & 27.92 & 31.66 \\
Aunque algunos salgan lastimados. & 24.26 & 29.45 \\
Aunque implique acciones no éticas. & 14.93 & 25.22 \\
Aunque se cometan injusticias. & 12.49 & 23.26 \\
Aunque se violen algunas leyes. & 9.63 & 21.42 \\
Aunque se violenten los derechos de algunos. & 6.78 & 17.98 \\
\hline Promedio Índice Económico & 12.94 & 12.73 \\
Promedio Índice Bioético & 92.16 & 14.12 \\
\hline
\end{tabular}

Todas las condiciones positivas recibieron porcentajes altos de acuerdo, y las condiciones negativas porcentajes bajos. Se calculó un índice de orientación sumando las respuestas a las condiciones negativas y restando las de las condiciones positivas. El resultado se convirtió a una escala porcentual. Mientras más alto el índice, más orientados están los participantes a conseguir las metas económicas de la empresa aunque ello suponga acciones ilegales o no éticas. Un índice bajo como el obtenido en los resultados refleja que los participantes favorecen conseguir las metas económicas, pero sin violentar los derechos de otros, cometer injusticias o actos no éticos, etc.

También se calculó un índice bioético en esta dimensión que resultó en un índice alto indicativo de que respetar los derechos de los otros, ser justos, no hacerle daño a otros y hacer algún bien social condicionan la orientación hacia las metas económicas. Este resultado reafirma lo obtenido en el análisis factorial en el que las dimensiones económicas, aunque importantes, no son las principales. Además, provee evidencia de que los participantes, sin necesa$80 \quad$ ISSN 1541-8561 
riamente tener conocimientos bioéticos, aplican sus principios intuitivamente para razonar sobre situaciones empresariales.

\section{Dimensión LegaL}

La Tabla 5 muestra los resultados obtenidos en la pregunta específica de la dimensión legal. Se les solicitó a los participantes que expresaran su acuerdo en términos porcentuales con la premisa: las empresas deben cumplir con todas las leyes, sujeto a 13 condiciones tales como: siempre, para evitar penalidades, para ser un buen ciudadano, etcétera. Al igual que en la pregunta anterior, las premisas relacionadas con condiciones un tanto negativas recibieron porcentajes bajos y las positivas, altos. Siguiendo el procedimiento anterior, se calculó el índice de orientación legal, el cual resultó relativamente alto y definitivamente más alto que el índice de orientación económica. La premisa que más acuerdo generó es que siempre se debe cumplir con la ley. Consistente con los resultados obtenidos en el análisis factorial, el cumplimiento de las leyes parece ser percibido como una forma de evitar daños.

Tabla 5 - Índice de Orientación Legal

\begin{tabular}{lcc}
\hline \multicolumn{1}{c}{ Premisas } & Promedio & $\begin{array}{c}\text { Desviación } \\
\text { Estándar }\end{array}$ \\
\hline Siempre & 93.96 & 15.38 \\
Para evitar causar daños a otros & 93.93 & 14.98 \\
Para respetar los derechos de los otros & 93.66 & 15.90 \\
Para evitar penalidades & 93.58 & 15.67 \\
Para defender los derechos de la empresa & 93.43 & 14.60 \\
Para hacerle bien a otros & 90.79 & 19.82 \\
Porque es lo justo & 90.17 & 19.48 \\
Porque es lo ético & 88.88 & 21.19 \\
Para ser un buen ciudadano & 87.94 & 23.65 \\
Y en algunos casos autoimponerse estándares más altos & 85.63 & 23.68 \\
Aunque se afecten las metas económicas & 80.66 & 28.50 \\
Porque resulta más económico que violarlas & 66.27 & 37.20 \\
Si no se afectan las metas económicas & 46.46 & 41.35 \\
\hline Promedio Índice Legal & 77.20 & 10.02 \\
Promedio Índice Bioético & 92.44 & 13.27 \\
\hline
\end{tabular}


Resultó interesante que las tres premisas de menor acuerdo son las relacionadas con condiciones económicas. Por un lado, cumplir con las leyes, aun a expensas de no lograr las metas económicas, recibió un acuerdo moderadamente alto; pero cumplir con las leyes si no se afectan las metas económicas, recibió un muy débil desacuerdo. Esto refleja cierta duda en los participantes y una cierta propensión a violentar algunas leyes, si hubiera alguna consideración económica tal vez importante. Sin embargo, cumplir con las leyes porque es más económico cumplirlas que violarlas recibió un acuerdo débil lo cual sugiere que la consideración económica no es muy importante para los participantes a la hora de cumplir con las leyes. Estos resultados sugieren que pudiera haber unas leyes particulares asociadas a unos costos económicos lo suficientemente altos como para que los participantes consideren violentar la ley.

El índice bioético calculado en esta dimensión también resultó alto. Este resultado sugiere que los participantes utilizan el razonamiento bioético como base para el cumplimiento legal. Resultaron particularmente importantes las premisas de evitar daños y respetar los derechos de otros, los cuales están relacionados con los principios de no maleficencia y de autonomía. Este resultado es cónsono con los anteriores respecto a la utilidad del razonamiento bioético en el mundo de los negocios.

\section{Dimensión ÉtICA}

La Tabla 6 muestra los resultados obtenidos en la pregunta específica de la dimensión ética. Se les solicitó a los participantes que expresaran su acuerdo en términos porcentuales con la premisa: las empresas deben actuar de forma ética, sujeto a 12 condiciones tales como: siempre, porque es lo justo, para mejorar la imagen de la empresa, etcétera.

$\mathrm{Al}$ igual que en la pregunta anterior, las premisas relacionadas con condiciones un tanto negativas recibieron porcentajes bajos y las positivas, altos, excepto la premisa de mejorar la imagen de la empresa, que recibió un acuerdo bastante elevado, a pesar de que a juicio de las autoras esa no debería ser una razón para actuar ética- 
mente, aun cuando es un valor agregado deseable. Las tres premisas vinculadas a condiciones un tanto negativas, recibieron porcentajes de acuerdo desde moderadamente alto hasta un débil desacuerdo. La premisa vinculada a comportarse éticamente, porque es una forma de aumentar las ganancias, recibió un acuerdo moderadamente alto, también en contra del juicio de las autoras, por la misma razón antes expuesta. Actuar éticamente, pero no más de lo requerido por ley, recibió un débil apoyo, lo que nos da a entender que para muchos participantes su visión de la ética es estrictamente legalista. La última, comportase éticamente sujeto a que no se afecten las metas económicas, recibió un débil desacuerdo sugiriendo que los participantes podrían actuar de forma no ética si las consecuencias económicas, a su juicio, lo ameritara.

Tabla 6 - Índice de Orientación Ética

\begin{tabular}{lcc}
\hline \multicolumn{1}{c}{ Premisas } & Promedio & $\begin{array}{c}\text { Desviación } \\
\text { Estándar }\end{array}$ \\
\hline Siempre & 92.70 & 19.51 \\
Para evitar causar daños a otros & 92.39 & 17.26 \\
Porque es lo justo & 88.61 & 22.63 \\
Para mejorar la imagen de la empresa & 88.52 & 22.05 \\
Para respetar la autonomía y dignidad de los otros & 87.91 & 22.76 \\
Para defender la autonomía de la empresa & 87.44 & 21.17 \\
Para hacerle bien a otros & 87.03 & 24.15 \\
Aunque implique más restricciones de las establecidas por ley & 85.26 & 25.68 \\
Aunque se afecten las metas económicas & 78.44 & 27.46 \\
Porque es una forma de aumentar las ganancias & 70.77 & 34.92 \\
Pero no más de lo que se le requiere por ley & 52.67 & 38.69 \\
Si no se afectan las metas económicas & 45.10 & 39.62 \\
\hline Promedio Índice Ético & 70.17 & 11.66 \\
Promedio Índice Bioético & 88.63 & 17.82 \\
\hline
\end{tabular}

Siguiendo el procedimiento anterior, se calculó el índice de orientación ética, el cual resultó moderadamente alto, pero el segundo más bajo de las cuatro dimensiones. La premisa que más acuerdo generó es que se debe actuar de forma ética siempre. Al igual que 
con el cumplimiento de las leyes, el comportamiento ético parece ser percibido como una forma de evitar causar daños. El índice bioético calculado en esta dimensión también resultó alto, aunque el más bajo de las cuatro dimensiones. Este resultado sugiere que los participantes utilizan el razonamiento bioético como complemento del razonamiento ético. Este resultado es cónsono con los anteriores respecto a la utilidad del razonamiento bioético en el mundo de los negocios.

\section{Dimensión de Libre DisCReción}

La Tabla 7 muestra los resultados obtenidos en la pregunta específica de la dimensión de libre discreción o social. Se les solicitó a los participantes que expresaran su acuerdo en términos porcentuales con la premisa: las empresas deben ser socialmente responsables, sujeto a 13 condiciones tales como: siempre, porque es lo justo, para obtener mayores ganancias, etcétera. Las premisas relacionadas con condiciones un tanto negativas recibieron porcentajes más altos de los esperados. La premisa sobre mejorar la imagen obtuvo un acuerdo alto, la de obtener mayores ganancias, un acuerdo moderadamente alto y la de si no se afectan las metas económicas, un débil acuerdo. La premisa, aunque se afecten las metas económicas, recibió un acuerdo relativamente alto. Tomadas en conjunto, estos resultados sugieren que los participantes entienden que las empresas deben ser socialmente responsables, pero posiblemente por las razones incorrectas. Además, el elemento económico podría ser un factor importante para alejarse de tal objetivo. 
EL RAZONAMIENTO BIOÉTICO Y LA ORIENTACIÓN HACIA RESPONSABILIDAD SOCIAL...

Tabla 7 - Índice de Orientación Social (Libre Discreción)

\begin{tabular}{lcc}
\hline \multicolumn{1}{c}{ Premisas } & Promedio & $\begin{array}{c}\text { Desviación } \\
\text { Estándar }\end{array}$ \\
\hline Para evitar causar daños a otros & 92.67 & 17.30 \\
Para respetar los derechos de los otros & 92.14 & 17.42 \\
Siempre & 91.11 & 19.69 \\
Porque es lo ético & 90.86 & 19.57 \\
Para mejorar su imagen & 90.66 & 19.77 \\
Porque es lo justo & 90.06 & 20.55 \\
Para hacerle bien a otros & 88.91 & 23.50 \\
Para ser un buen ciudadano & 88.80 & 22.81 \\
Para defender los derechos de la empresa & 86.65 & 22.49 \\
Porque es parte de sus funciones & 81.91 & 27.04 \\
Para obtener mayores ganancias & 81.08 & 28.51 \\
Aunque se afecten las metas económicas & 74.67 & 31.67 \\
Si no se afectan las metas económicas & 53.64 & 39.56 \\
\hline Promedio Índice de Orientación Social & 73.38 & 12.36 \\
Promedio Índice Bioético & 90.09 & 16.29 \\
\hline
\end{tabular}

Se calculó el índice de orientación social, el cual resultó moderadamente alto. La premisa que más acuerdo generó es que las empresas deben ser socialmente responsables para evitar causarles daños a otros. El índice bioético calculado en esta dimensión también resultó alto. Este resultado sugiere que los participantes utilizan el razonamiento bioético como justificación para que las empresas sean socialmente responsables. Una vez más este resultado reafirma la utilidad del razonamiento bioético en el mundo de los negocios.

\section{RELACIÓN DE LOS ÍNDICES}

La Tabla 8 muestra las correlaciones entre los índices calculados y los coeficientes de confiabilidad, en la línea diagonal. Todos los coeficientes de confiabilidad exceden el .70 aceptado y defendido por Nunally and Bernstein (1994) como el mínimo deseable, excepto uno, que excede el .60 aceptado para estudios exploratorios. Todas las correlaciones son significativas al 99\% de confianza. 
Tabla 8 - Correlaciones y Coeficientes de Confiabilidad de los Índices*

\begin{tabular}{lcccccccccr}
\hline & 1 & 2 & 3 & 4 & 5 & 6 & 7 & 8 & 9 & 10 \\
\hline 1. RSE & $(.91)$ & & & & & & & & & \\
2. Económico & -.357 & $(.71)$ & & & & & & & & \\
3. Legal & .601 & -.546 & $(.76)$ & & & & & & & \\
4. Ético & .462 & -.572 & .596 & $(.88)$ & & & & & & \\
5. Social & .656 & -.489 & .625 & .691 & $(.87)$ & & & & & \\
6. Bioético General & .784 & -.335 & .626 & .430 & .576 & $(.62)$ & & & & \\
7. Bioético-Económico & .573 & -.590 & .597 & .470 & .526 & .530 & $(.79)$ & & & \\
8. Bioético-Legal & .657 & -.420 & .817 & .401 & .568 & .711 & .599 & $(.84)$ & & \\
9. Bioético-Ética & .646 & -.441 & .615 & .623 & .691 & .637 & .625 & .696 & $(.81)$ & \\
10. Bioético-Social & .752 & -.388 & .625 & .501 & .852 & .654 & .561 & .705 & .763 & $(.86$ \\
\hline
\end{tabular}

Todas las correlaciones son significativas a $\mathrm{p}<.010$

* Los coeficientes de confiablidad Chronbach's Alpha se muestran en la línea diagonal entre paréntesis

Todos los índices tienen una correlación inversa con el índice económico y positivo entre los demás. En términos generales, esto sugiere que cuanto más orientado se esté hacia las otras dimensiones de la empresa, o cuanto más presente esté el razonamiento bioético, menos orientado se estará hacia las metas económicas y viceversa. Las tres correlaciones más altas del índice económico fueron con los índices bioético - económico, ético y legal. Esto sugiere que cuanto más se consideren los principios bioéticos y las dimensiones éticas y legales de la empresa, menos orientado estará el individuo hacia las metas económicas. Dicho de otra forma, el razonamiento bioético, ético y legal ofrecen límites, o tal vez dirección, a la función económica de la empresa.

Las correlaciones positivas más altas, sobre .80 , se dieron entre el índice social y el bioético social y entre el legal y el bioético legal. Esto sugiere que el razonamiento bioético sirve como justificación para la función social de la empresa y para el cumplimiento con las leyes y normativas vigentes. Otras correlaciones importantes (mayores de .75) se dieron entre el índice de responsabilidad social empresarial y el índice bioético general y el bioético social, y este último con el índice bioético-ético. Esto sugiere una fuerte relación entre el razonamiento bioético y la función social y ética de las empresas. 


\section{Comparación de Empresas Exitosas y Socialmente Responsables}

Se les solicitó a los participantes que, de un listado de 15 características, indicaran en términos porcentuales cuáles de estas eran necesarias para catalogar a una empresa como exitosa y como socialmente responsable. La Tabla 9 presenta los resultados a esta pregunta, incluyendo la diferencia en los promedios obtenidos y su nivel de significancia.

Tabla 9 - Características de Empresas Exitosas y Socialmente Responsables

\begin{tabular}{|c|c|c|c|c|c|c|}
\hline \multirow{2}{*}{ Premisas } & \multicolumn{2}{|c|}{ Empresa Exitosa } & \multicolumn{2}{|c|}{$\begin{array}{c}\text { Empresa Socialmente } \\
\text { Responsable }\end{array}$} & \multirow{2}{*}{ Diferencia } & \multirow{2}{*}{ Significancia } \\
\hline & Promedio & $\begin{array}{l}\text { Desviación } \\
\text { Estándar }\end{array}$ & Promedio & $\begin{array}{l}\text { Desviación } \\
\text { Estándar }\end{array}$ & & \\
\hline Es eficiente. & 96.93 & 10.85 & 84.06 & 25.44 & 12.86 & .000 \\
\hline Es competitiva. & 96.43 & 11.72 & 75.63 & 30.63 & 20.79 & .000 \\
\hline $\begin{array}{l}\text { Maximiza } \\
\text { ganancias de } \\
\text { accionistas. }\end{array}$ & 92.44 & 52.38 & 63.42 & 34.89 & 29.15 & .000 \\
\hline Produce riqueza. & 92.43 & 18.31 & 69.10 & 33.28 & 23.25 & .000 \\
\hline Es lucrativa. & 90.96 & 18.85 & 71.11 & 31.84 & 19.80 & .000 \\
\hline $\begin{array}{l}\text { Mejoramiento de } \\
\text { sus internos. }\end{array}$ & 90.50 & 18.22 & 85.53 & 24.87 & 5.03 & .021 \\
\hline $\begin{array}{l}\text { Cumple con todas } \\
\text { las leyes. }\end{array}$ & 88.60 & 21.50 & 92.35 & 19.09 & -3.75 & .013 \\
\hline $\begin{array}{l}\text { Es justa en sus } \\
\text { operaciones. }\end{array}$ & 87.63 & 21.37 & 92.53 & 18.04 & -4.98 & .006 \\
\hline $\begin{array}{l}\text { Derechos de los } \\
\text { internos. }\end{array}$ & 87.34 & 20.59 & 89.49 & 22.95 & -2.30 & .263 \\
\hline $\begin{array}{l}\text { Opera de forma } \\
\text { ética. }\end{array}$ & 85.49 & 23.29 & 95.51 & 14.27 & -10.02 & .000 \\
\hline $\begin{array}{l}\text { Estándares de } \\
\text { excelencia. }\end{array}$ & 85.08 & 27.03 & 89.76 & 23.20 & -4.98 & .026 \\
\hline $\begin{array}{l}\text { Derechos de los } \\
\text { externos. }\end{array}$ & 83.03 & 26.10 & 93.89 & 15.52 & -10.83 & .000 \\
\hline $\begin{array}{l}\text { No le causa daños } \\
\text { a otros. }\end{array}$ & 82.42 & 25.68 & 95.75 & 13.64 & -13.31 & .000 \\
\hline $\begin{array}{l}\text { Mejoramiento de la } \\
\text { sociedad. }\end{array}$ & 79.64 & 26.61 & 94.55 & 15.13 & -14.87 & .000 \\
\hline \multirow[t]{2}{*}{ Estándares éticos. } & 78.09 & 30.29 & 90.55 & 21.22 & -12.56 & .000 \\
\hline & Promedio & $\begin{array}{l}\text { Desviación } \\
\text { Estándar }\end{array}$ & $\begin{array}{l}\text { Confiabili- } \\
\text { dad }\end{array}$ & Promedio & $\begin{array}{c}\text { Des- } \\
\text { viación } \\
\text { Estándar }\end{array}$ & Confiabilidad \\
\hline Todas las Premisas & 87.86 & 14.89 & .863 & 85.32 & 14.29 & .867 \\
\hline Premisas Bioéticas & 84.94 & 18.85 & .891 & 91.95 & 13.41 & .808 \\
\hline
\end{tabular}


Hubo diferencias significativas, al .010 de significancia en 11 premisas, al .050 en tres premisas y solo en una la diferencia no fue significativa. Esto sugiere que a los que, según los participantes, se requieren unas características para que la empresa sea exitosa y otras para ser socialmente responsable lo cual refleja que podrían ser metas mutuamente excluyentes. Lo más importante para que la empresa sea exitosa es que sea eficiente, competitiva, que maximice la ganancia de los accionistas, que produzca riqueza, que sea lucrativa y contribuya al mejoramiento de sus constituyentes internos. Todo parece indicar que los participantes definen el éxito de una empresa en términos económicos. Las características menos importantes para que la empresa sea exitosa son que contribuya al mejoramiento de los grupos externos y de la sociedad, y que se autoimponga estándares éticos más allá de los requeridos por ley. Esto reafirma que el éxito no se mide por la función social o el comportamiento ético de las empresas. Parece ser que basta con cumplir con la ley.

Las características más importantes para ser una empresa socialmente responsable son: no causarle daño a otros, operar en forma ética, contribuir al mejoramiento de los grupos externos y de la sociedad, respetar los derechos de los grupos de interés externos, ser justas en sus operaciones y actividades, cumplir con todas las leyes, y autoimponerse estándares éticos más allá de los requerido por ley. Cuatro de las cinco premisas de razonamiento bioético fueron seleccionadas como de las más necesarias para ser socialmente responsables y las dos premisas relativas al comportamiento ético. Los participantes entienden la responsabilidad social de las empresas como aquel comportamiento ético sensible a las necesidades de los grupos de interés y el bienestar de la sociedad. Las menos necesarias son maximizar la ganancia de los accionistas, producir riqueza, ser lucrativas y ser competitivas. Parecería que los participantes perciben a las empresas socialmente responsables como organizaciones sin fines de lucro, un tanto incapaces de ser lucrativas o producir riqueza.

La única característica que no fue identificada contundentemente con una alternativa o la otra fue el respetar los derechos de los constituyentes internos, la cual identificaron como bastante necesaria. Es decir, respetar a los empleados está por encima de otras conside- 
raciones. Contribuir al mejoramiento de los constituyentes internos y autoimponerse estándares de excelencia fueron premisas bastante favorecidas que reflejan diferencias menos significativas. Esto sugiere nuevamente que los participantes entienden que la empresa está obligada a atender las necesidades de sus empleados y a perseguir la excelencia como meta deseable.

Al comparar los promedios obtenidos en todas las premisas y en las premisas de razonamiento bioético, se encontró que las premisas bioéticas se perciben más necesarias para que las empresas sean socialmente responsables que para que sean exitosas. Todos los coeficientes de confiabilidad sobrepasaron el valor de .80, lo cual demuestra una alta confiabilidad en la escala.

\section{Comparaciones POR GÉNero}

Se realizaron pruebas Whitney $\mathrm{U}$ para detectar diferencias en todas las respuestas debido al género. Sólo se encontraron cinco diferencias significativas al nivel .050 de significancia, las cuales se muestran en la Tabla 10. En términos generales, no parece haber mucha diferencia entre la percepción de los hombres y las mujeres respecto a los tópicos examinados.

Las mujeres dan más importancia a que se destinen parte de las ganancias de la empresa a actividades benéficas, lo cual refleja un mayor sentido filantrópico. Las mujeres le otorgan más importancia a la función de los directivos de evitar causar daños a otros. A su vez, esto refleja una inclinación a ser más cuidadosas en sus acciones que los hombres. Las mujeres están ligeramente más de acuerdo que los hombres con la premisa de que las metas económicas deben lograrse haciendo un bien social, lo cual muestra que el principio de beneficencia es favorecido más entre ellas. Las mujeres presentaron un acuerdo mayor con la premisa que establece que las empresas deben cumplir siempre con las leyes. Esto revela una inclinación más fuerte hacia el cumplimiento legal. Por último, las mujeres obtuvieron una puntuación más alta que los hombres en el índice bioético calculado en la dimensión económica, lo cual sugiere que el razonamiento bioético influye un tanto más en su orientación económica. 
Tabla 10 - Diferencias debido al Género

\begin{tabular}{lcccc}
\hline Premisas & Hombres & Mujeres & Diferencia & Significancia \\
\hline $\begin{array}{l}\text { Razón de ser de las Empresas } \\
\text { Destinar ganancias a actividades benéficas. }\end{array}$ & 69.94 & 74.87 & 4.93 & .045 \\
\hline $\begin{array}{l}\text { Funciones de los Directivos } \\
\text { Evitar daños a otros con sus acciones u omisiones. }\end{array}$ & 88.99 & 96.00 & 7.01 & .012 \\
\hline $\begin{array}{l}\text { Las metas económicas deben lograrse } \\
\text { Haciendo algún bien social. }\end{array}$ & 82.03 & 85.76 & 3.73 & .033 \\
\hline $\begin{array}{l}\text { Deben cumplir con todas las leyes } \\
\text { Siempre. }\end{array}$ & 90.96 & 95.79 & 4.83 & .030 \\
\hline $\begin{array}{l}\text { Índices } \\
\text { Índice Bioético - Económico. }\end{array}$ & 90.91 & 92.87 & 1.96 & .012 \\
\hline
\end{tabular}

\section{Comparaciones por Nivel Educativo}

Las pruebas conducidas para detectar diferencias debido al nivel educativo resultaron en 27 diferencias significativas al nivel .010 de significancia y 18 al nivel .050 para un total de 45 , lo cual significa aproximadamente $40 \%$ de las variables examinadas. En la Tabla 11 se presentan estos resultados. En todos los casos el promedio de los estudiantes subgraduados fue mayor que el de los estudiantes graduados.

Los estudiantes subgraduados le otorgan alrededor de 10\% más de importancia a todas las premisas que componen la dimensión social de las empresas que los estudiantes graduados, en consecuencia reconocen mejor la función social de las empresas. En la misma dirección, los estudiantes subgraduados le otorgan casi un $20 \%$ más de importancia a la responsabilidad de los directivos y la empresa con los grupos de interés externos; poco más de un 10\% adicional a la responsabilidad con los grupos internos, y casi un $25 \%$ más a la responsabilidad de resolver problemas sociales, en comparación con los estudiantes graduados en torno a estas premisas. 
EL RAZONAMIENTO BIOÉTICO Y LA ORIENTACIÓN HACIA RESPONSABILIDAD SOCIAL...

Tabla 11 - Diferencias debido al Nivel Educativo

\begin{tabular}{|c|c|c|c|c|}
\hline Premisas & Subgraduado & Graduado & Diferencia & Significancia \\
\hline \multicolumn{5}{|l|}{ Razón de ser de las Empresas } \\
\hline Ayudar a resolver problemas sociales & 88.18 & 76.39 & 11.78 & .007 \\
\hline Beneficiar a diversos grupos & 85.62 & 74.29 & 11.33 & .008 \\
\hline Destinar ganancias a actividades benéficas & 76.31 & 61.05 & 15.26 & .018 \\
\hline Mejorar la calidad de vida de la sociedad & 89.46 & 75.66 & 13.81 & .005 \\
\hline Mejorar la calidad de vida de su comunidad & 88.85 & 74.84 & 14.00 & .003 \\
\hline Ser reconocida como una empresa ética & 94.24 & 83.42 & 10.81 & .003 \\
\hline Ser reconocida como socialmente responsable & 95.42 & 84.74 & 10.68 & .000 \\
\hline \multicolumn{5}{|l|}{ Funciones de los Directivos } \\
\hline Defender el derecho de la empresa a elegir & 87.66 & 78.82 & 8.84 & .038 \\
\hline Procurar el mejoramiento de grupos externos & 84.53 & 65.66 & 18.87 & .000 \\
\hline Procurar el mejoramiento de los internos & 92.73 & 79.74 & 12.99 & .002 \\
\hline Resolver problemas sociales & 83.11 & 59.13 & 23.98 & .000 \\
\hline \multicolumn{5}{|l|}{ Las metas económicas deben lograrse } \\
\hline Haciendo algún bien social & 87.15 & 74.21 & 12.94 & .028 \\
\hline Sin importar los medios para lograrlo & 32.93 & 17.50 & 15.43 & .015 \\
\hline \multicolumn{5}{|l|}{ Deben cumplir con todas las leyes } \\
\hline Para defender los derechos de la empresa & 94.86 & 87.97 & 6.89 & .047 \\
\hline Para hacerle bien a otros & 94.36 & 77.76 & 16.60 & .017 \\
\hline Porque es lo ético & 91.39 & 79.61 & 11.78 & .017 \\
\hline Si no se afectan las metas económicas & 49.85 & 33.16 & 16.70 & .019 \\
\hline \multicolumn{5}{|l|}{ Las empresas deben actuar de forma ética } \\
\hline Para defender la autonomía de la empresa & 90.15 & 77.76 & 12.38 & .011 \\
\hline Para evitar causar daños a otros & 94.01 & 86.58 & 7.44 & .036 \\
\hline Para hacerle bien a otros & 91.38 & 71.58 & 19.80 & .001 \\
\hline Para respetar la autonomía de los otros & 91.38 & 75.53 & 15.85 & .008 \\
\hline Premisas & Subgraduado & Graduado & Diferencia & Significancia \\
\hline \multicolumn{5}{|l|}{ Deben ser socialmente responsables } \\
\hline Para defender los derechos de la empresa & 89.65 & 75.92 & 13.73 & .021 \\
\hline Para evitar causar daños a otros & 94.27 & 86.95 & 7.32 & .039 \\
\hline Para hacerle bien a otros & 92.32 & 76.71 & 15.61 & .004 \\
\hline Para mejorar su imagen & 92.82 & 82.89 & 9.93 & .005 \\
\hline Para obtener mayores ganancias & 84.47 & 68.95 & 15.52 & .029 \\
\hline Porque es parte de sus funciones & 85.49 & 69.08 & 16.41 & .002 \\
\hline Si no se afectan las metas económicas & 57.71 & 39.08 & 18.63 & .013 \\
\hline
\end{tabular}


Tabla 11 - Diferencias debido al Nivel Educativo - Continuación

\begin{tabular}{lcccc}
\hline \multicolumn{1}{c}{ Premisas } & Subgraduado & Graduado & Diferencia & Significancia \\
\hline \multicolumn{1}{c}{ Empresa Exitosa } & & & & \\
\hline Respeta los derechos de grupos externos & 85.57 & 73.55 & 12.02 & .006 \\
Respeta los derechos de sus internos & 89.70 & 78.55 & 11.15 & .033 \\
Se auto impone estándares éticos & 82.29 & 62.50 & 19.79 & .002 \\
Se exige estándares de excelencia & 89.68 & 68.11 & 21.58 & .001 \\
\hline \multicolumn{1}{c}{ Empresa Socialmente Responsable } & & & & \\
\hline Contribuye al mejoramiento de sus internos & 89.04 & 72.76 & 16.27 & .004 \\
Es competitiva & 78.54 & 64.61 & 13.93 & .020 \\
Es eficiente & 89.20 & 65.26 & 23.94 & .000 \\
Es justa en sus operaciones y actividades & 94.90 & 83.95 & 10.95 & .009 \\
Maximiza ganancias accionistas & 67.34 & 48.24 & 19.09 & .006 \\
\hline \multicolumn{1}{c}{ Índices } & & & & \\
\hline Bioético & 90.34 & 82.13 & 8.22 & .001 \\
Bioético - Legal & 94.29 & 85.73 & 8.56 & .036 \\
Bioético - Ética & 91.28 & 79.23 & 12.05 & .004 \\
Bioético - Social & 92.30 & 82.18 & 10.12 & .004 \\
Empresa Exitosa & 89.69 & 81.08 & 8.61 & .023 \\
Empresa Responsable & 87.28 & 78.15 & 9.13 & .004 \\
Bioética - Responsable & 93.36 & 86.83 & 6.52 & .015 \\
Responsabilidad Social Empresarial & 89.69 & 84.84 & 4.85 & .039 \\
\hline
\end{tabular}

Si bien ambos grupos están en desacuerdo con que las metas económicas deben lograse sin importar los medios para lograrlo, los estudiantes subgraduados presentan casi el doble de desacuerdo que los estudiantes graduados. De igual forma, ambos grupos están en desacuerdo con que se debe cumplir con todas las leyes, si no, se afectan las metas económicas, pero lo expresado por los estudiantes graduados es casi $20 \%$ mayor que el de los subgraduados que prácticamente reflejaron neutralidad en su respuesta. Los estudiantes subgraduados justifican las acciones éticas de las empresas sobre las bases de beneficencia, autonomía y no maleficencia más que los estudiantes graduados. 
Aunque los estudiantes subgraduados parecen estar más en sintonía con la responsabilidad social de las empresas que los estudiantes graduados, esto podría ser por las razones equivocadas. Los resultados reflejan que los subgraduados están más de acuerdo que los graduados en cuanto a que las empresas deben ser socialmente responsables para mejorar sus imagen (10\% más), obtener mayores ganancias (15\% más) o si no se afectan las metas económicas (casi $20 \%$ más).

Los estudiantes subgraduados perciben como más necesario que las empresas respeten los derechos de sus grupos de interés y se autoimpongan estándares éticos y de excelencia superiores a los exigidos por ley que los estudiantes graduados. Entienden, también, más que los graduados, que es más necesario para las empresas ser eficientes, competitivas y maximizar la ganancia de los accionistas para ser socialmente responsables.

Dada las diferencias antes discutidas no es sorprendente que los subgraduados estén más orientados a la responsabilidad social de las empresas que los graduados. Los resultados reflejan, además, que los subgraduados utilizan más el razonamiento bioético para analizar las dimensiones empresariales que los graduados.

\section{Análisis de los Resultados}

Los resultados de este estudio validan parcialmente las cuatro dimensiones propuestas por Carroll (1979), pero no como las establece teóricamente. En todas las dimensiones, excepto en las económicas, están presentes el razonamiento bioético y las consideraciones éticas. Los resultados del análisis factorial sugieren que los participantes perciben como más importantes las obligaciones sociales de la empresa por encima de las obligaciones legales o económicas. Sin embargo, en los resultados de la importancia de las funciones de los directivos, la más importante es el cumplimiento legal, y luego operar de forma ética, cumplir con las metas económicas y resolver problemas sociales. Esto revela un claro desfase entre lo que los participantes perciben como los objetivos de las empresas y los objetivos de los ejecutivos que las dirigen. 
Este estudio avanzó un paso más al medir la orientación de cada una de las dimensiones teóricas por separado. Según los índices calculados, los participantes están más orientados a la función legal, luego a la social, seguida de la dimensión ética y, por último, a la económica. En todas las dimensiones el razonamiento bioético está presente y los participantes le otorgan una gran importancia. Se puede concluir que los participantes reconocen las diversas obligaciones de la empresa ante diversos grupos en particular y con la sociedad en general. No obstante, ello no implica necesariamente que favorezcan contribuir al desarrollo de estrategias de responsabilidad social empresarial en su futura carrera profesional. Tampoco están orientados a cumplir las metas económicas y alcanzar la maximización de las ganancias de los accionistas como plantea la visión tradicional de las empresas. Más bien, están enfocados prioritariamente al cumplimiento legal, seguido de los aspectos éticos y sociales y, por último, al desempeño económico.

Sin embargo, los participantes parecen definir el éxito de las empresas en términos primordialmente económicos, en contraposición a la sensibilidad ética y social con la que parecen definir las empresas socialmente responsables. Esto implica que si los participantes no están orientados hacia las metas económicas, tampoco están orientados hacia hacer exitosas las empresas que dirijan en un futuro. Una inferencia razonable de estos resultados es que los participantes parecen resolver la tensión que les causa el éxito económico, por un lado, y tener una conducta ética y sensible socialmente, por el otro, usando el marco legal como un referente para justificar sus acciones y las de las empresas.

Las diferencias significativas encontradas entre los estudiantes graduados y subgraduados sugieren que los estudiantes subgraduados reconocen la dimensión social de las empresas más que los graduados. Una posible explicación es que los estudiantes graduados, normalmente, han tenido experiencias laborales que los subgraduados aún no han tenido. Esto podría implicar que en "el mundo real" las empresas siguen teniendo como objetivo principal la maximización de ganancias y la función social ocupa un lugar menos importante, si acaso, por lo que los egresados ajustan su visión a la de la empresa en la que laboran. En la misma línea, los estudiantes subgraduados 
utilizan más los principios bioéticos que los graduados para analizar las funciones y el comportamiento deseable de las empresas, al igual que sus responsabilidades como directivos. Presumiendo que ninguno de los grupos ha estado expuesto al estudio formal de la bioética y que su utilización es más bien intuitiva, se podría concluir que una vez en el ambiente laboral, los valores personales quedan supeditados a los valores corporativos.

Tomados en conjunto, los resultados sugieren que los futuros directivos de empresas no están comprometidos ni con las metas económicas de la organización ni con utilizar los recursos de la empresa para responder a las necesidades de los diversos actores sociales. Parecen utilizar el marco normativo como un referente neutral en el que se opera en un punto medio y todas las partes quedan satisfechas. Por lo tanto, los futuros directivos reflejan una visión en la que el mundo de los negocios es un juego, sin objetivos precisos, pero con reglas claras. En consecuencia, el único objetivo es permanecer en el juego simplemente siguiendo las reglas establecidas.

Ello implica un gran reto para las escuelas de negocios donde se supone que se formen los recursos humanos para ejercer sus profesiones. Parece ser que la exposición de los estudiantes al tema de la responsabilidad social empresarial es efectiva en la transmisión de conceptos teóricos. No obstante, las diferencias entre estudiantes subgraduados y graduados sugieren que tales conceptos no se convierten en valores personales lo suficientemente arraigados como para contrarrestar valores corporativos contrarios. Por tal razón, los egresados, en vez de ser líderes y agentes de cambio, se convierten, en su iniciación en el campo laboral, en seguidores del continuismo. Es necesario que las escuelas de negocios expongan a los estudiantes no sólo a todas las corrientes de pensamiento moral, sino que deben proveerles experiencias que les permitan apropiarse e internalizar tales justificaciones éticas. Aquí se ha demostrado que la inclusión del estudio de la bioética podría enriquecer el currículo de las escuelas de negocio, añadiendo una herramienta adicional para desarrollar la responsabilidad social empresarial de las empresas. 


\section{Conclusiones}

Este estudio logró los seis objetivos propuestos. Primero, se determinó la importancia de los principios bioéticos en la definición de lo que constituye una empresa. Los resultados demostraron que todos los principios bioéticos fueron relevantes e importantes. Segundo, se confirmó parcialmente la validez de las cuatro dimensiones del modelo de Carroll (1979) y su importancia relativa. Tercero, se calcularon índices para medir la orientación hacia la responsabilidad social empresarial y cada una de las cuatro dimensiones teóricas, teniendo todos altos niveles de confiabilidad. Se calcularon índices de razonamiento bioético con un alto grado de confiabilidad y se identificó su relación con los índices de las cuatro dimensiones de la empresa, lo cual redundó en relaciones positivas, excepto con la dimensión económica, y significativas en todas las instancias. Se identificaron las características que deben tener las empresas para ser consideradas exitosas, socialmente responsables, y el efecto de los principios bioéticos para lograrlo. Se encontró que el éxito de las empresas se define principalmente por variables económicas y las socialmente responsables, por su sensibilidad social y ética. Los principios bioéticos resultaron más importantes para definir las empresas socialmente responsables que las exitosas. Sexto, se identificaron cinco diferencias significativas debido al género, en las que los promedios de las mujeres siempre fueron más altos, lo cual refleja una sensibilidad mayor de ellas respecto a los hombres. También, se identificaron 45 diferencias significativas debido al nivel educativo, en las que los estudiantes subgraduados revelaron mayor sensibilidad social y razonamiento bioético en todas las instancias.

Todo estudio confronta ciertas limitaciones que deben ser informadas. Dado que la muestra no fue seleccionada aleatoriamente, los resultados no pueden, y no han sido, generalizados a la población. Como en todo cuestionario autocumplimentado, es posible que las respuestas ofrecidas por los participantes no necesariamente reflejen su sentir completamente.

Independientemente de los avances logrados en la investigación de la responsabilidad social empresarial, aún quedan muchas preguntas por responder. Sigue siendo necesario elaborar instrumentos 
EL RAZONAMIENTO BIOÉTICO Y LA ORIENTACIÓN HACIA RESPONSABILIDAD SOCIAL...

de medición válidos y confiables. Dado la complejidad de los conflictos éticos de estos tiempos, es necesario continuar haciendo estudios multidisciplinarios que provean nuevas y variadas perspectivas que permitan mejorar la formación de los futuros directivos y empresarios. Este estudio pretende ser un pequeño paso en esa dirección. 


\section{Referencias}

Angelidis, J., \& Ibrahim, N. (2004). An exploratory study of the impact of degree of religiousness upon an individual's corporate social responsiveness orientation. Journal of Business Ethics, 51(2), 119-128.

Arlow, P. (1991). Personal characteristics in college students' evaluations of business ethics and corporate social responsibility. Journal of Business Ethics, 10(1), 63.

Aupperle, K. E. (1991). The use of forced-choice survey procedures in assessing corporate social orientation. En L. E. Preston (Ed.), Research in corporate social performance and policy (Vol. 12, pp. 269-279). Greenwich, CT: JAI Press.

Aupperle, K. E., Carroll, A., \& Hatfield, J. (1985). An empirical examination of the relationship between corporate social responsibility and profitability. Academy of Management Journal, 28, 446463.

Aupperle, K., \& Simmons, F. (1989). Have CEO's of large US firms changed their CSR orientation during the Reagan presidency? Trabajo presentado en el Academy of Management Meetings, Washington D.C.

Beauchamp, T. (2007). The 'four principles' approach to health care ethics. En R. E. Ashcroft, A. Dawson, H. Draper, \& J. R. McMillan (Eds.), Principles of health care ethics (2da ed.). Chichester, UK: John Wiley \& Sons. doi: 10.1002/9780470510544.ch1

Beauchamp, T., \& Childress, J. (1979). Principles of biomedical ethics (1st-5th eds.). New York: Oxford University Press.

Burton, B., \& Harvey Hegarty, W. (1999). Some determinants of student corporate social responsibility orientation. Business and Society, 38(2), 188-205.

Burton, B., Jiing-LihFarh, K., \& Harvey Hegarty, W. (2000). A crosscultural comparison of corporate social responsibility orientation: Hong Kong vs. United States Students. Teaching Business Ethics, 4(2), 151. 
Carroll, A. B. (1979). A three-dimensional conceptual model of corporate social performance. Academy of Management Review, 4, 497-506.

Carroll, A. B. (1991). Corporate social performance measurement: A commentary on methods for evaluating an elusive construct. En L. E. Preston (Ed.), Research in corporate social performance and policy (Vol. 12, pp. 385-401). Greenwich, CT: JAI Press.

Clarkson, M. (1995). A stakeholder framework for analyzing and evaluating corporate social performance. Academy of Management Review, 20, 92-117.

Cohen, J., Pant, L., \& Sharp, D. (1998). The effect of gender and academic discipline diversity on the ethical evaluations, ethical intentions and ethical orientation of potential public accounting recruits. Accounting Horizons, 12, 250-270.

De la Cruz, M., \& Cabrera, M. (8-9 de junio de 2007). El desarrollo de la ética y la responsabilidad social a través del gobierno corporativo. Trabajo presentado en el XV Congreso Nacional de Ética de la Economía y de las Organizaciones. El Buen Gobierno de las Organizaciones. IESE Business School, Barcelona, España.

Di Biase De Lillo. (2005). Responsabilidad social empresarial. Recuperado de http://www.cyta.com.ar/biblioteca/bddoc/bdlibros/rse/334_rse_franco.pdf

Donaldson, T., \& Preston, L. (1995). The stakeholder theory of the corporation: concepts, evidence, and implications. Academy of Management Review, 20(1), 65-91.

Fisher, J. (2001). Lessons for business ethics from bioethics. Journal of Business Ethics, 34, 15-25.

Freeman, R. E. (1984). Strategic management. A stakeholder approach. Boston: Pitman/Ballinger (Harper Collins).

Freeman, R., \& Velamuri, S. R. (2006). A new approach to CSR: Company stakeholder responsibility. En A. Kakabadse, \& M. Morsing (Eds.), Corporate social responsibility reconciling aspiration with application (pp. 9-23). Great Britain: Palgrave Mcmillan.

Friedman, M. (1970). The social responsibility of business is to increase its profits. New York Times Magazine, 13, 122-126. 
Gump, L., \& Baker, R. (2000). Cultural and gender differences in moral judgment: A study of Mexican Americans and AngloAmericans. Hispanic Journal of Behavioral Science, 22, 78-94.

Heath, J., \& Norman, W. (2004). Stakeholder theory, corporate governance and public management: What can the history of state-run enterprises teach us in the post-Enron era? Journal of Business Ethics, 53, 247-265.

Ibrahim, N., \& Angelidis, J. (1993). Corporate social responsibility: A comparative analysis of perceptions of top executives and business students. The Mid-Atlantic Journal of Business, 29(3), 303-315.

Ibrahim, N., \& Angelidis, J. (1995). The corporate social responsiveness orientation of board members: Are there differences between inside and outside directors? Journal of Business Ethics, 14, 405-410.

Ibrahim, N., Angelidis, J., \& Howard, D. (2006). Corporate social responsibility: A comparative analysis of perceptions of practicing accountants and accounting students. Journal of Business Ethics, 66(2-3), 157-167.

Ibrahim, N., Angelidis, J., \& Howard, D. (2008). The relationship between religiousness and corporate social responsibility orientation: Are there differences between business managers and students? Journal of Business Ethics, 78(1-2), 165-174.

Kliskberg, B. (2010). RSE: Una mirada desde América Latina. Recuperado de http://sociedadinformacion.fundacion.telefonica. $\mathrm{com} /$ telos $/$ cuadernograbar.asp@idarticulo=5\&rev=79.htm.

Lämsä, A. M., Vehkaperä, M., Puttonen, T., \& Pesonen, H. L. (2008). Effect of business education on women and men students' attitudes on corporate responsibility in society. Journal of Business Ethics, 82(1), 45-58.

Luthar, H., \& Ranjan, K. (2005). Exposure to ethics education and the perception of linkage between organizational ethical behavior and business outcomes. Journal of Business Ethics, 61, 353368. 
McGee, R., \& López-Paláu, S. (2008). Tax evasion and ethics: A comparative study of the USA and four Latin American countries. In Taxation and public finance in transition and developing economies. Estados Unidos: Springer.

Nunnally, J., \& Bernstein, I. (1994). Psychometric theory (3rd ed.). New York: McGraw-Hill.

Okada, Y., \& Watanabe, K. (2008). Social responsibility for the use of genes, genomes, and biotechnology in biotechnology companies: A commentary from the bioethical viewpoint. Journal of Commercial Biothechnoly, 14(2), 149-168.

O’Neill, H. M., Saunders, C., \& McCarthy, A. (1989). Board members, corporate social responsiveness and profitability: Are tradeoffs necessary? Journal of Business Ethics, 8, 353-357.

Patterson, D. (1994). A model of ethical/unethical decision-making by auditors in the big six accounting firms. (Disertación doctoral no publicada). Georgia State University, Atlanta, EU.

Pinkston, T. S., \& Carroll, A. (1996). A retrospective examination of CSR orientations: Have they changed? Journal of Business Ethics, 15, 199-206.

Porter, M., \& Kramer, M. (2011). Creating shared value: How to reinvent capitalism and unleash a wave of innovation and growth. Harvard Business Review.

Porter, M., \& Kramer, M. (2006). Estrategia y sociedad: El nexo entre la estrategia competitiva y la responsabilidad social de la empresa. Harvard Business Review.

Post, J., Preston, L., \& Sachs, S. (2002). Managing the extended enterprise: the new stakeholder view. California Management Review, 45(1), 6-28.

Ramiro, P., \& Pulido, A. (2009). Análisis de la responsabilidad social corporativa de las empresas transnacionales en Colombia. OMAL - Asociación Paz con Dignidad. Recuperado en enero de 2010, de http:/ /alainet.org/active/34275\&lang=es

Roxas, M., \& Stoneback, J. (2004). The importance of gender across cultures in ethical decision-making. Journal of Business Ethics, 50, 149-165. 
Santos y Vargas, L. (2006). Bioética crítica. Puerto Rico: Instituto Hostosiano de Bioética.

Singhapakdi, A., Vitell, S., Rallapalli, K., \& Kraft, K. (1996). The perceived role of ethics and social responsibility: A scale development. Journal of Business Ethics, 15, 1131-1140.

Sleeper, B., Kenneth, C., Schneider, P., \& Weber, J. (2006). Scale and study of student attitudes toward business education's role in addressing social issues. Journal of Business Ethics, 68(4), 381391.

Vives, A. (2011). Si no está roto no lo arregles: Porter y Kramer sobre RSE. Recuperado de ExPok News: http://www.expoknews.com

Wicks, A. (1995). The business ethics movement: Where are we headed and what we can learn from our colleagues in bioethics. Business Ethics Quarterly, 5, 603-621. 